\title{
Micromethod for bleeding time in the newborn
}

\author{
J M RENNIE, T GIBSON, AND R W I COOKE \\ Regional Neonatal Intensive Care Unit, University of Liverpool, Liverpool Maternity Hospital
}

SUmmary A new method of measuring bleeding time using an Autolet device is described. Normal ranges of bleeding time and volume of blood used in the test have been defined in a population including preterm babies. Abnormal values have been shown in newborns with a variety of problems, and an abnormality of bleeding time has been found to precede intraventricular haemorrhage.

Bleeding time has long been recognised as a useful in vivo test of platelet-capillary function, but its measurement has been performed infrequently on neonates. Techniques for measurement have been varied: Duke's original earlobe stab did not include venostasis but recognised the importance of the platelet in cessation of bleeding; ${ }^{1}$ venostasis was later added by Ivy to improve the sensitivity of the technique. ${ }^{2}$ Further developments have been in the use of templates, ${ }^{3}$ but the smallest template designed for the newborn requires the infliction of a 5 $\mathrm{mm}$ by $0.5 \mathrm{~mm}$ deep incision on the forearm. ${ }^{4}$ In the tiniest infants this is a substantial wound with a risk of scarring and is therefore unsuitable for repeated observations. In view of the clinical need for an in vivo test of capillary-platelet interaction in situations such as sepsis, intraventricular haemorrhage, and administration of drugs known to have effects on the prostaglandin pathway, a less traumatic method has been devised. Previous work has suggested that the Autolet device reduces emotional sweating associated with capillary blood sampling ${ }^{5}$ and we therefore used this in a standardised way to measure bleeding time in the newborn.

\section{Population and methods}

Observations were made on 104 babies admitted to the Liverpool Regional Neonatal Intensive Care Unit over a nine month period. Fifty two of the infants were clinically stable and receiving no drugs known to interfere with bleeding time; observations on these babies served to define the normal range. Distribution of the babies' gestational ages is shown in Table 1. Gestational ages ranged from 24 weeks to term, and birthweight from $834 \mathrm{~g}$ to $3500 \mathrm{~g}$. Most observations were made in the first three days of life, although the range was from three hours to 17 days. The study was approved by the local ethical
Table 1 Distribution of observations by gestational age

\begin{tabular}{lc}
\hline Gestational age & No \\
\hline $26-30$ & 16 \\
$31-32$ & 16 \\
$33-34$ & 10 \\
$35-$ term & 8 \\
Total & 52 \\
\hline
\end{tabular}

committee. Venous occlusion of the forearm was obtained by inflating a disposable plastic cuff (EME) with a mercury sphygmomanometer. Pressures used were appropriate to the baby's weight ${ }^{4}$ $20 \mathrm{~mm} \mathrm{Hg}$ for those less than $1000 \mathrm{~g} ; 25 \mathrm{~mm} \mathrm{Hg} 1000$ to $2000 \mathrm{~g}$; and $30 \mathrm{~mm} \mathrm{Hg}$ greater than $2000 \mathrm{~g}$ - and produced visible venous distension. A standardised incision was produced on the cleaned skin of the thumb using an Autolet device (Owen Mumford). Blood was absorbed from the incision every few seconds with filter paper until the flow ceased; time to cessation of bleeding being recorded with a stopwatch.

The filter paper was eluted in a measured volume of Isoton (physiological saline with preservatives to prevent bacterial overgrowth). The haemoglobin was converted to cyanmethaemoglobin, and the haemoglobin of the solution measured by colorimetry. From the baby's haemoglobin measurement the same day the volume of blood eluted could be calculated. Volume estimations were made on a total of 82 estimations. Platelet counts and haemoglobin estimations were made as part of routine care.

\section{Results}

Normal range. In the well babies there was no correlation between bleeding time and gestational age, age at estimation, or birthweight. In 37 an 


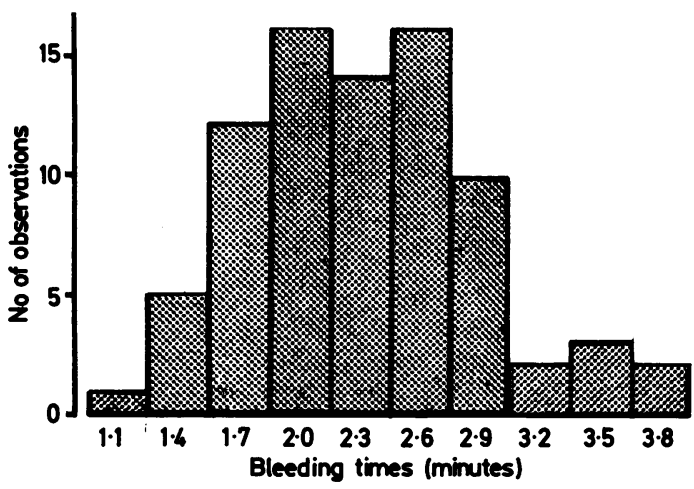

Fig. 1 Distribution of normal bleeding times.

observation was made on a single occasion, and in the remainder serial observations were made on successive days. Thus a total of 82 observations form the histogram for definition of normal bleeding time (Fig. 1); $97 \%$ of these observations fall below 3.5 minutes, which is therefore taken as the upper limit of normal.

Reproducibility. Duplicate observations were performed in the same baby at the same time on 30 occasions. Variation, expressed as the difference between the two results as a percentage of the larger result, varied from $0 \%$ to $32 \%$, with mean variation $9 \%$. On 25 of the occasions the variation was less than $10 \%$.

The reproducibility of the method is, therefore, acceptable, and to minimise trauma the punctures were single at a given time thereafter.

Volume estimations. The volume of blood eluted from babies with a normal bleeding time was always less than $0.15 \mathrm{ml}$ : the volume of blood eluted from babies with a prolonged bleeding time was much greater, the mean being $0.27 \mathrm{ml}$. Student's $t$-test applied to the means clearly shows two populations (Table 2).

Abnormal bleeding time. Twenty seven of the babies studied who were ill were identified with a prolongation of bleeding time, often on several occasions.

Table 2 Means of volumes of blood $(\mathrm{ml})$ eluted from babies with normal and abnormal bleeding times

\begin{tabular}{llll}
\hline & No & Mean & (SD) \\
\hline $\begin{array}{l}\text { Normal bleeding time } \\
(<3.5 \text { minutes })\end{array}$ & 52 & $0 \cdot 10$ & $0 \cdot 10$ \\
$\begin{array}{c}\text { Abnormal bleeding time } \\
(>3.5 \text { minutes })\end{array}$ & 26 & 0.27 & $0 \cdot 22$ \\
\hline
\end{tabular}

Students $t$ test on means, $\mathrm{P}=0.001$
Clinical problems included severe respiratory distress syndrome, exchange transfusion, sepsis, liver failure, and birth asphyxia. Many of these babies had a low platelet count but in seven the bleeding time was long when the platelet count was normal, suggesting an abnormality of function rather than number. These 7 infants had a median gestational age of 27 weeks and were all receiving respiratory support for hyaline membrane disease. All 7 developed ultrasound scan evidence of periventricular haemorrhage, and two subsequently died.

The relation between platelet count and bleeding time is shown in Fig. 2. Ten of the babies with a prolonged bleeding time subsequently died, reflecting the severity of the associated illness. During the five month period from October 1983 to February 1984 a total of 33 babies who subsequently developed intraventricular haemorrhage had bleeding times measured before the bleed occurred. Fifteen of these measurements were abnormal, confirming the association between intraventricular haemorrhage and prolonged bleeding time noted by Setzer et $a l,{ }^{6}$ and also showing that the disturbance of platelet-capillary interaction seen with intraventricular haemorrhage is not always a secondary phenomenon as has been suggested. ${ }^{7}$ It is of note that all the babies whose initial bleed was parenchymal were in this group.

\section{Discussion}

Measurement of bleeding time by this method is simple and rapid to perform with sterile disposable equipment and causes minimal disturbance to the infant, who remains in his own incubator. In several infants on transcutaneous monitoring no alteration in $\mathrm{TcPO}_{2}$ could be seen. The device is cheap and easily obtainable. Use of the thumb as the chosen site for puncture avoids problems associated with laceration of superficial forearm veins, ${ }^{8}$ and it is

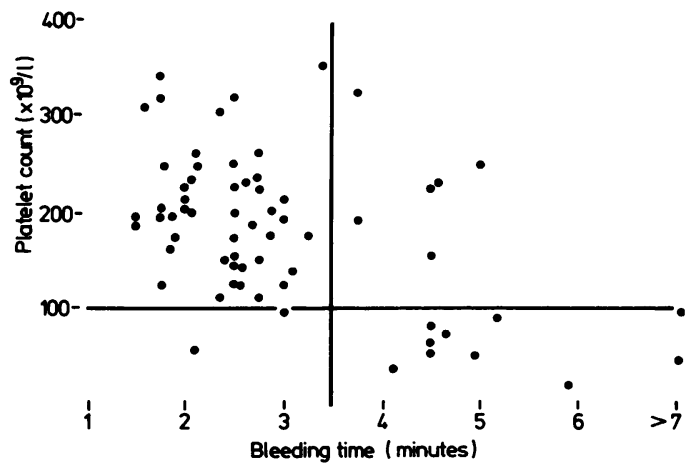

Fig. 2 Scatterplot of platelet count against bleeding time. 
easier to maintain an even pressure while activating the device.

The method gives a bleeding time which is slightly shorter than previous work.9 Large numbers of observations have not been made on preterm babies in the past, and previous workers mainly used template methods, which tend to give longer bleeding times than stab incisions (Table 3 ). The addition of volume estimations by an observer unaware of the bleeding time has served to confirm the reliability of the method, and the abnormal results. Few previous attempts, and none in neonates, have been made to measure the volume of blood used in the test and these gave widely differing figures, from $0 \cdot 005 \mathrm{ml}$ to $13 \mathrm{ml}^{10}{ }^{11}$

Neonatal platelets are known to be normal in number but to have impaired function, with abnormal adenosine diphosphate aggregation, ${ }^{12}$ possibly due to a 'storage pool' rather than an aspirin-like defect. ${ }^{13}$ Bleeding time has been found to be normal in previous studies and the present study supports this finding, showing that in the well neonate the functional abnormality of platelet function does not affect platelet-capillary integrity.

Disturbances of coagulation, however, are an extremely common problem in the newborn, ${ }^{14}$ with reduced $\mathrm{Cr}-51$ platelet survival shown in ill neonates. ${ }^{15}$ Previous attempts at correction have not been successful in improving mortality. ${ }^{16-18}$ One study showed a reduction in the incidence of intraventricular haemorrhage after correction, ${ }^{19}$ but this diagnosis was by necropsy, now known to be inaccurate in the estimation of the incidence of the condition. ${ }^{20}$ The present study suggests that measurement of bleeding time may identify those infants most at risk of intraventricular haemorrhage, and thus those in whom the administration of prophylactic agents would be most appropriate. In addition, the measurement of bleeding time, made easier by the use of a micromethod, will assist in the

Table 3 Comparison of bleeding times, methods, and patients in previous studies

\begin{tabular}{|c|c|c|}
\hline Author & $\begin{array}{l}\text { Bleeding time } \\
\text { (minutes) }\end{array}$ & Note \\
\hline Duke $1910^{\prime}$ (range) & $1-3$ & Ear lobe stab \\
\hline Ivy $1941^{2}$ (mean) & $0 \cdot 4$ & $\begin{array}{l}\text { Forearm stab with } \\
\text { venostasis, many did } \\
\text { not bleed. }\end{array}$ \\
\hline Harker $1972^{3}$ (mean (SD)) & $4.5(1.5)$ & Template, adults \\
\hline $\begin{array}{l}\text { Mull and Hathaway } 1970^{9} \\
(\text { mean (SD)) }\end{array}$ & $4 \cdot 05(0 \cdot 33)$ & $\begin{array}{l}\text { Spring lancet, forearm. } \\
\text { neonates, none } \\
\text { pretermı }\end{array}$ \\
\hline Sutor $1970^{11}$ (mean (SD)) & $3 \cdot 18(0 \cdot 5)$ & Template, adults \\
\hline Feusner $1980^{-}$(mean (SD)) & $3 \cdot 4(1 \cdot 3)$ & $\begin{array}{l}\text { Template, some } \\
\text { neonates, } 6 \text { preterm }\end{array}$ \\
\hline Setzer $1982^{\circ}$ (mean (SD)) & $3 \cdot 3(0 \cdot 2)$ & $\begin{array}{l}\text { Simplate template } \\
\text { included preterms }\end{array}$ \\
\hline
\end{tabular}

study of abnormalities induced by agents such as indomethacin and phototherapy. The normal range established may also help to confirm suspected coagulation defects in infants in whom venepuncture is difficult and laboratory studies, therefore, unreliable or unobtainable.

\section{References}

${ }^{1}$ Duke WW. The relationship of blood platelets to haemorrhagic disease. JAMA 1910;60:1185-92.

2 Ivy AG, Nelson D. Bucher G. The standardisation of certain factors in the cutaneous venostasis bleeding time technique. J Lab Clin Med 1941;26:1812-22.

${ }^{3}$ Harker LA, Slichter SJ. The bleeding time as a screening test for evaluation of platelet function. $N$ Engl J Med 1972:287: 155-9.

${ }^{4}$ Feusner JH. Normal and abnormal bleeding times in neonates and young children utilising a fully standardised template technique. Am J Clin Pathol 1980;74:73-7.

5 Harpin V, Rutter N. Making heel pricks less painful. Arch Dis Child 1983;58:226-8.

- Setzer ES, Webb IB, Wassenaar JW, Reeder JD, Mehta PS, Eitzman DV. Platelet dysfunction and coagulopathy in intraventricular hacmorrhage in the premature infant. $J$ Pediatr 1982;100:599-65.

7 Chessels JM, Wigglesworth JS. Coagulation studies in preterm infants with respiratory distress and intracranial haemorrhage. Arch Dis Child 1972;47:564-70.

${ }^{8}$ Mielke CH. Aspirin prolongation of the template bleeding time: influence of venostasis and direction of incision. Blood 1982;60:1139-42.

${ }^{9}$ Mull MM, Hathaway WE. Altered platelet function in newborns. Pediatr Res 1970:4:229-37.

${ }^{10}$ Willoughby MLN, Allington MJ. The rate of blood loss from skin puncture during the Ivy bleeding time test. J Clin Pathol 1961:14:381-4.

"Sutor AH, Bowie EJW, Thompson JH. Didisheim P. Mertens BF, Owen CA. Bleeding from standardised skin punctures: automated technique for recording time, intensity and pattern of bleeding. Am J Clin Pathol 1971;55:541-50.

12 Stuart MJ. Platelet function in the neonate. Am J Pediatr Hematol Oncol 1979;1:227-34.

13 Stuart MJ. The neonatal platelet. Br J Haematol 1978;39:83.

14 Barnard DR, Simmons MA, Hathaway WE. Coagulation studies in extremely premature infants. Pediatr Res 1979;13:1330-5

15 Feusner JH, Slichter SJ, Harker LA, Acquired haemostatic defects in the ill newborn. Br J Haematol 1983;53:73-84.

16 Waltl H, Fodich HJ, Kurz R, Hohenauer L, Mittersteicler G, Rossler H. Intracranial haemorrhage in low birth weight infants and prophylactic administration of coagulation factor concentrate. Lancet 1973;i:1284-5.

${ }^{17}$ Hambleton G, Appleyard WJ. Controlled trial of FFP in asphyxiated low birthweight infants. Arch Dis Child 1973;48: 31-5.

${ }^{18}$ Gray OP, Ackerman A, Fraser AJ. Intracranial hacmorrhage and clotting defects in low birthweight infants. Lancet 1968;i:545-9.

19 Turner T, Prowse CV, Prescott RJ, Cash JD. A clinical trial on the early detection and correction of haemostatic defects in selected high-risk neonates. Br J Haematol 1981;47:65-75.

20 Papile L, Burstein J, Koffler H. Incidence and evolution of subependymal and intraventricular hacmorrhage. J Pediatr 1978;92:529.

Correspondence to Dr R W I Cooke, Regional Neonatal Intensive Care Unit, Liverpool Maternity Hospital, Liverpool L7 7BN.

Received 24 September 1984 